\title{
ANALISIS KINERJA PEGAWAI PADA BIRO PEMERINTAHAN DAN OTONOMI DAERAH SEKRETARIAT DAERAH PROVINSI KALIMANTAN TENGAH
}

\section{ANALYSIS OF EMPLOYEE PERFORMANCE AT THE BUREAU OF GOVERNMENT AND REGIONAL AUTONOMY OF THE REGIONAL SECRETARIAT OF CENTRAL KALIMANTAN PROVINCE}

\section{Dian Widhi Pratama}

\section{R.Biroum Bernardianto \\ Rachmat Hidayat}

Universitas Muhammadiyah Palangkaraya, Palangka Raya, Indonesia

*email:

dianwidhipratama@gmail.com

\section{Kata Kunci:}

Kinerja

Pegawai

Biro

\section{Keywords:}

Performance

Employees

Bureau

\begin{abstract}
Abstrak
Penelitian ini dilaksanakan pada Biro Pemerintahan dan Otonomi Daerah Sekretariat Daerah Provinsi Kalimantan Tengah, hal ini bertujuan untuk mengetahui kinerja pegawai negeri sipil pada Biro Pemerintahan dan Otonomi Daerah Sekretariat Daerah Provinsi Kalimantan Tengah.

Penelitian ini menggunakan data primer yang diambil dengan 56 (lima puluh enam) orang dengan cara sensus. Dari hasil analisis yang peneliti lakukan dapat dilihat bahwa Kinerja Pegawai Negeri Sipil pada Biro Pemerintahan dan Otonomi Daerah Sekretariat Daerah Provinsi Kalimantan Tengah pada taraf baik, hal ini pada semua variabel penelitian yaitu Pengetahuan Tentang Pekerjaan, Kualitas Kerja, Produktivitas, Adaptasi, Inisiatif dan Pemecahan Masalah, Kerjasama, Tanggungjawab dan Kemampuan dalam Berkomunikasi dan Berinteraksi. Berdasarkan kriteria penilaian yang ditetapkan maka dapat disimpulkan bahwa Analisis Kinerja Pegawai Negeri Sipil Pada Biro Pemerintahan dan Otonomi Daerah Sekretariat Daerah Provinsi Kalimantan Tengah tergolong baik.

Hal yang dapat direkomendasikan dalam penelitian ini seperti pengelolaan organisasi yang hanya menekankan pada pendekatan prosedur, tetapi harus disempurnakan melalui perubahan visi dan misi, pendekatan, strategi dan kegiatan operasional agar dapat tercipta kerjasama tim yang prima, hubungan kerja berdasarkan pendekatan partisipasi dan kelompok kerja (teamwork) guna dapat mencapai misi organisasi yang efisiensi, efektif dan menuju ke arah yang lebih baik.
\end{abstract}

\section{Abstract}

This research was conducted at the Bureau of Government and Regional Autonomy of the Regional Secretariat of Central Kalimantan Province, it aims to determine the performance of civil servants in the Bureau of Government and Regional Autonomy of the Regional Secretariat of Central Kalimantan Province.

The study used primary data taken with 56 (fifty-six) people by census. From the results of the analysis that the researchers conducted can be seen that the Performance of Civil Servants in the Bureau of Government and Regional Autonomy of the Regional Secretariat of Central Kalimantan Province at a good level, this is in all variables of research, namely Knowledge about Work, Quality of Work, Productivity, Adaptation, Initiative and Problem Solving, Cooperation, Responsibility and Ability in Communicating and Interacting. Based on the assessment criteria set, it can be concluded that the Performance Analysis of Civil Servants in the Bureau of Government and Regional Autonomy of the Regional Secretariat of Central Kalimantan Province is relatively good.

Things that can be recommended in this study such as organization management that only emphasizes on the approach of procedures, but must be refined through changes in vision and mission, approach, strategy and operational activities in order to create excellent teamwork, working relationships based on participation approaches and work groups (teamwork) in order to achieve the mission of an organization that is efficient, effective and heading in a better direction.
} 


\section{PENDAHULUAN}

Penilaian kinerja adalah suatu kegiatan yang dilakukan manajemen penilai untuk menilai kinerja tenaga kerja dengan cara membandingakan kinerja atas kinerja dengan uraian/deskripsi pekerjaan dalam suatu periode tertentu biasanya setiap akhir tahun. Kegiatan ini dimaksudkan untuk mengukur kinerja masing-masing tenaga kerja dalam mengembangkan kulitas kerja, pembinaan selanjutnya, tindakan perbaikan atas pekerjaan yang kurang sesuai deskripsi pekerjaan, serta untuk keperluan yang berhubungan dengan masalah ketenagakerjaan lainnya.

Sedangkan fenomena kinerja pegawai yang ada di lingkungan Biro belum seperti yang diharapkan, hal ini bisa dilihat dari pegawai yang kurang menanggapi prosedur yang sudah ditetapkan oleh Biro Pemerintahan dan Otonomi Daerah Sekretariat Daerah Provinsi Kalimantan Tengah, sehingga masih banyaknya pegawai yang pada saat jam kerja tidak berada ditempat. Hal ini juga diakibatkan ketidaksesuaian latar belakang pendidikan dengan pekerjaaan yang dilakukan, ada pegawai yang berlatarbelakang pendidikan SMA tetapi pekerjaanya mengarsip surat dan secara nyata dapat dilihat dari kondisi-kondisi yang ditemukan sebagai berikut : prosedur administrasi belum berjalan sebagaimana mestinya, penerapan prosedur administrasi proyek yang kurang sesuai dengan ketentuan yang berlaku, pemberian tugas tidak sesuai dengan latarbelakang yang dimiliki pegawai, jadwal pelaksanaan proyek pembangunan yang tidak tepat waktu, adanya keengganan pegawai untuk bekerja lebih optimal.

Berdasarkan pengamatan dilapangan dari segi disiplin waktu bekerja masih ditemukannya pegawai yang kurang memanfaatkan waktu secara baik, hal ini dilihat masih adanya pegawai hadir lewat dari waktu yang telah ditetapkan seharusnya jam masuk kantor adalah pukul 07.00 WIB pagi tetapi hadir pukul 08.00 WIB pagi, begitu juga pada saat jam makan siang dan istirahat pukul 12.00-13.00 WIB tetapi pada kenyataannya masih ditemukannya pegawai yang masuk kembali ke kantor pukul I4.00 WIB bahkan ada juga yang pukul I4.30 WIB. Disamping itu juga pegawai dalam menyikapi pekerjaan lebih kepada cepat selesai, sehingga ditemukannya kurang ketelitian pegawai dankurangnya kemauan yang kuat dalam mempelajari tugas dan kewajibannya.

Biro Pemerintahan dan Otonomi Daerah Sekretariat Daerah Provinsi Kalimantan Tengah sebagai suatu instansi pemerintahan yang berhubungan langsung dalam meningkatkan pelayanan yang ada di provinsi tersebut, dalam perannya Biro Pemerintahan dan Otonomi Daerah Sekretariat Daerah Provinsi Kalimantan Tengah mempunyai tugas penting dalam mempersiapkan perumusan kebijakan daerah, pengoordinasian pelaksanaan tugas Perangkat Daerah, pemantauan dan evaluasi pelaksanaan kebijakan di bidang pemerintahan, otonomi daerah dan kerja sama. Oleh, karena itu pegawai Biro Pemerintahan dan Otonomi Daerah Sekretariat Daerah Provinsi Kalimantan Tengah hendaknya dapat meningkatkan kinerjanya agar kualitas kinerja meningkat dan capaian kinerja memiliki nilai yang baik dari tahun ke tahun.

Kinerja Pegawai di Biro Pemerintahan dan Otonomi Daerah Sekretariat Daerah Provinsi Kalimantan Tengah tergambar dari Hasil Evaluasi Hasil Pelaksanaan Renja SKPD dan Pencapaian Renstra SKPD s/d Tahun 2020 (tahun berjalan) Biro Pemerintahan, sebagai berikut :

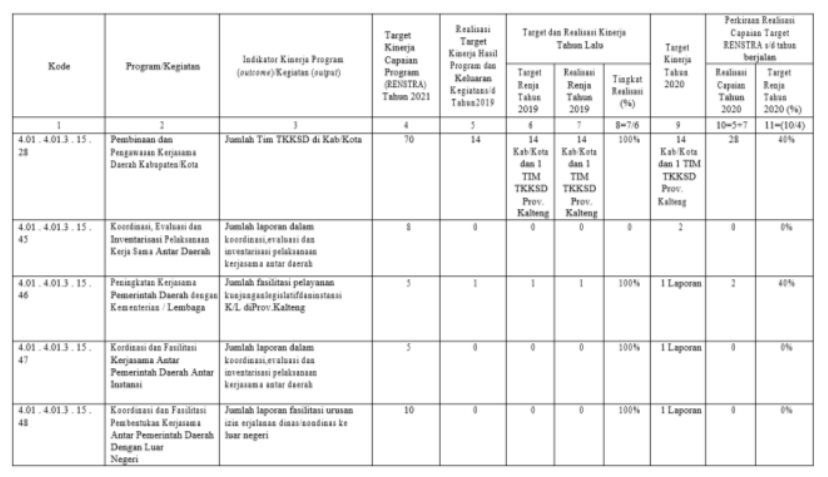




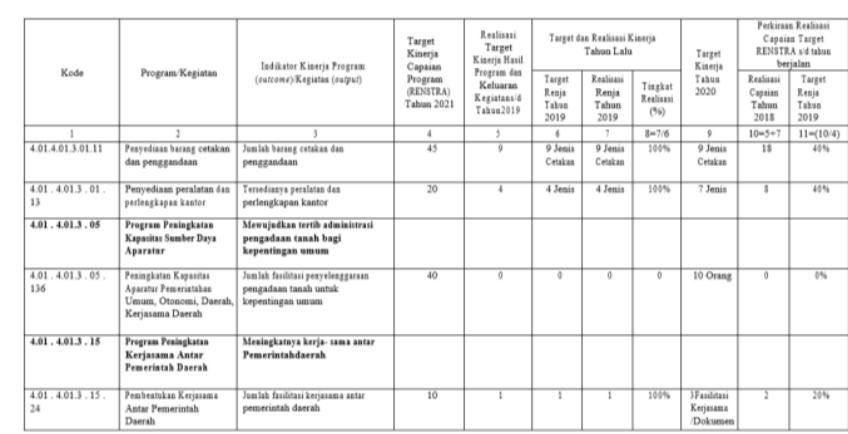

Dari tabel diatas dapat disimpulkan bagaimana gambaran kinerja Pegawai Negeri Sipil pada Biro Pemerintahan dan Otonomi Daerah Sekretariat Daerah Provinsi Kalimantan Tengah secara umum dapat dilihat dari beberapa aspek dan salah satunya adalah dari Pengukuran Pencapaian Sasaran (PPS) Biro Pemerintahan dan Otonomi Daerah Sekretariat Daerah Provinsi Kalimantan Tengah pada tahun 2020 ini. Masih terlihat banyaknya target perencanaan yang belum tercapai sesuai dengan yang diharapkan. Pada kondisi ini diasumsikan bahwa kinerja pegawai dan semangat pegawai dalam melaksanakan tugas dan program pemerintah kurang maksimal dan budaya kerja pula mengakibatkan semakin rendahnya pencapaian target tersebut.

Selanjutnya jenjang pendidikan juga sangat mempengaruhi kinerja seseorang, karena latar belakang ini memiliki dampak yang sangat kuat dalam membentuk sikap dan mental seorang pekerja yang handal (profesional) dan pekerja keras. Keaktifannya dalam bekerja bukan berdasarkan pada materi, tetapi sudah diarahkan kepada pembentukan prestasi dan produktivitas. Adapun tingkat pendidikan Pegawai pada Biro Pemerintahan dan Otonomi Daerah Sekretariat Daerah Provinsi Kalimantan Tengah, sebagai berikut :

Tabel 2. Jenjang Pendidikan Pegawai

\begin{tabular}{|l|l|l|l|}
\hline No & $\begin{array}{l}\text { Tingkat Pendidikan } \\
\text { Pegawai }\end{array}$ & \multicolumn{2}{|l|}{ Jumlah (Orang) } \\
\hline & & Laki-Laki & Perempuan \\
\hline I. & SD & - & - \\
\hline 2. & SMP & - & - \\
\hline 3. & SMA & 4 & 5 \\
\hline 4. & DI/D2/D3 & - & - \\
\hline 5. & SI & 26 & 15 \\
\hline
\end{tabular}

\begin{tabular}{|l|l|l|l|}
\hline 6. & S2 & 2 & 4 \\
\hline Jumlah & 32 & 24 \\
\hline
\end{tabular}

Sumber : Sub Bagian Tata Usaha pada Biro Pemerintahan dan Otonomi Daerah Tahun 2020 yang sudah diolah.

Berdasarkan tabel diatas dapat diketahui bahwa latar belakang pendidikan pegawai pada Biro Pemerintahan dan Otonomi Daerah Sekretariat Daerah Provinsi Kalimantan Tengah lebih didominasi oleh pegawai dengan jenjang pendidikan sarjana (SI) dan didominasi oleh laki-laki. Jenjang pendidikan tentu berimplikasi pada kinerja serta pemahaman atas pekerjaan yang dijalankan oleh pegawai yang bersangkutan. Jika dilihat dari latar belakang pendidikan yang dimiliki pegawai pada Biro Pemerintahan dan Otonomi Daerah Sekretariat Daerah Provinsi Kalimantan Tengah, maka dapat dikatakan cukup baik karena melihat situasi dan kondisi sosial, ekonomi serta persoalan yang terjadi pada masyarakat saat ini sangat kompleks, sehingga sangat diperlukan upaya-upaya untuk memberikan pendidikan dan pelatihan kepada mereka agar dapat bekerja lebih optimal didalam menjalankan roda pemerintahan.

Tingkat kehadiran pegawai Biro Pemerintahan dan Otonomi Daerah Sekretariat Daerah Provinsi Kalimantan Tengah pada tahun 2020 merupakan salah satu faktor yang utama dalam pencapaian tujuan organisasi. Akan tetapi pada situasi Pandemi Covid 19 tingkat kehadiran pegawai menjadi tidak maksimal dikarenakan pengaturan kehadiran kerja $50 \%$ dan beberapa kali kejadian isolasi kantor terkait kasus pegawai yang terpapar Covid 19. Indikator kehadiran pegawai di kantor tidak dapat dijadikan gambaran kinerja dan tentunya sangat tidak sesuai dengan kondisi ideal sesuai dengan harapan.

\section{METODOLOGI}

Jenis Penelitian ini adalah penelitian Desktiptif dengan pendekatan analisis frekuensi data yang berusaha memberikan gambaran kinerja pegawai negeri sipil pada Biro Pemerintahan dan Otonomi Daerah Sekretariat 
Daerah Provinsi Kalimantan Tengah berdasarkan persepsi pegawai.

Analisis frekuensi data hasil penelitian dilakukan secara kuantitatif berdasarkan 8 (delapan) indikator terhadap variabel Kinerja sesuai konsep operasional variabel berupa aspek Pengetahuan Tentang Pekerjaan, Kualitas Kerja, Produktivitas, Adaptasi, Inisiatif dan Pemecahan Masalah, Kerjasama, Tanggungjawab dan Kemampuan dalam Berkomunikasi dan Berinteraksi.

Penelitian ini dilakukan di Kantor Biro Pemerintahan dan Otonomi Daerah Sekretariat Daerah Provinsi Kalimantan Tengah pada Tahun 2020. Pemilihan lokasi penelitian ini berdasarkan pertimbangan penulis ingin mengetahui bagaimana Kinerja Pegawai pada Biro Pemerintahan dan Otonomi Daerah Sekretariat Daerah Provinsi Kalimantan Tengah.

Populasi pada penelitian ini adalah pegawai negeri sipil yang bekerja pada Biro Pemerintahan dan Otonomi Daerah Sekretariat Daerah Provinsi Kalimantan Tengah yang berjumlah 30 (tiga puluh) PNS dan 26 (dua puluh enam) orang merupakan Pegawai dengan Perjanjian Kontrak, dan seluruhnya ditetapkan sebagai sampel penelitian sebanyak 56 (lima puluh enam) orang pegawai negeri sipil dan Pegawai dengan Perjanjian Kontrak.

Adapun Data primer dalam penelitian ini yaitu data yang diperoleh dari responden dengan menggunakan kuesioner, wawancara dan observasi. Data ini meliputi data atau informasi tentang kinerja pegawai dan tanggapan Responden terhadap kinerja pegawai dalam meningkatkan kerja pegawai. Sedangkan Data sekunder, yaitu data yang diperoleh dari Biro Pemerintahan dan Otonomi Daerah Sekretariat Daerah Provinsi Kalimantan Tengah yang berupa : Struktur organisasi, pendidikan pegawai, jumlah pegawai, dan rincian tugas pokok serta fungsi pegawai.

\section{HASIL DAN PEMBAHASAN}

Adapun data yang diolah dalam penelitian ini adalah data terkait Analisis Kinerja Pegawai Negeri Sipil pada Biro Pemerintahan dan Otonomi Daerah Sekretariat Daerah
Provinsi Kalimantan Tengah. Responden dalam penelitian ini adalah seluruh Pegawai Negeri Sipil yang bekerja pada Biro Pemerintahan dan Otonomi Daerah SekretariatDaerah Provinsi Kalimantan Tengah sebanyak 56 (lima puluh enam) orang yang terdiri dari 30 (tiga puluh ) orang PNS dan 26 (dua puluh enam) orang pegawai dengan perjanjian kontrak. Dari hasil penelitian telah terkumpul sejumlah data yang diperlukan, data identitas responden, dan tanggapan responden tentang variabel analisis kinerja pegawai negeri sipil pada Biro Pemerintahan dan Otonomi Daerah Sekretariat Daerah Provinsi Kalimantan Tengah.

Tabel 4.I.

Karakteristik Responden Berdasarkan Jenis Kelamin

\begin{tabular}{|l|l|l|l|}
\hline No & Jenis Kelamin & Jumlah & Persentase (\%) \\
\hline I. & Laki-Laki & 26 Orang & $45 \%$ \\
\hline 2. & Perempuan & 30 Orang & $59 \%$ \\
\hline \multicolumn{2}{|l|}{ Jumlah } & 56 Orang & $100 \%$ \\
\hline
\end{tabular}

Sumber: Data Biro Pemerintahan dan Otonomi Daerah Sekretariat Pemerintah Daerah Provinsi Kalimantan Tengah Tahun 2020 yang sudah diolah.

Dari Tabel di atas dapat dilihat Jenis Kelamin responden laki-laki sebanyak 26 orang (45\%) dan perempuan sebanyak 30 orang (59\%). Hal ini menunjukkan bahwa pegawai negeri sipil yang bekerja pada Biro Pemerintahan dan Otonomi Daerah Sekretariat Daerah Provinsi Kalimantan Tengah lebih didominasi oleh perempuan dibandingkan laki-laki.

Tabel 4.3. Karakteristik Responden Berdasarkan Tingkat Pendidikan

\begin{tabular}{|c|c|c|c|}
\hline No & $\begin{array}{c}\text { Tingkat } \\
\text { Pendidikan }\end{array}$ & Jumlah & Persentase (\%) \\
\hline I. & Doktoral & 0 & $0 \%$ \\
\hline 2. & Magister & 6 & $10 \%$ \\
\hline 3. & Sarjana & 4 I & $74 \%$ \\
\hline 4. & Diploma & 0 & $0 \%$ \\
\hline 5. & SLTA & 9 & $16 \%$ \\
\hline \multicolumn{2}{|c|}{ Jumlah } & 56 & 100 \\
\hline
\end{tabular}

Sumber : Tata Usaha Biro Pemerintahan dan Otonomi Daerah Sekretariat Daerah Provinsi Kalimantan Tengah Tahun 2020 yang sudah diolah. 
Dari tabel diatas diketahui tingkat pendidikan pegawai Negeri Sipil dan Pegawai Kontak dengan Perjanjian Kerja pada Biro Pemerintahan dan Otonomi Daerah Sekretariat Daerah Provinsi Kalimantan Tengah, yaitu terdapat 6 orang (10\%) pegawai yang berpendidikan S2, kemudian $4 \mathrm{I}$ orang (74\%) tamatan SI dan diikuti dengan 0 pegawai (0\%) tamatan Diploma, serta yang terakhir 9 orang (16\%) pegawai yang tamatan SLTA. Hal ini dapat disimpulkan bahwa tingkat pendidikan pegawaisudah cukup baik, dimana pegawai yang pendidikannya tinggi mampu memberikan pengarahan bagi pegawai yang belum mengerti sepenuhnya tentang pekerjaan.

\section{Rekapitulasi dan Analisis Data Kinerja}

Untuk membahas masing-masing indikator dari variabel kinerja Pegawai negeri sipil pada Biro Pemerintahan dan Otonomi Daerah Sekretariat Daerah Provinsi Kalimantan Tengah digunakan kuesioner yang disebarkan kepada responden dalam penelitian ini. Pertanyaan-pertanyaan didalam variabel menyangkut tentang analisis kinerja pegawai dengan berdasarkan indikator-indikator yang telah dikemukakan pada Bab II penelitian ini. Berdasarkan pada perhitungan ke delapan (8) indikator, maka selanjutnya penulis membuat tabel rekapitulasi dari Analisis Kinerja Pegawai Negeri Sipil pada Biro Pemerintahan dan Otonomi Daerah Sekretariat Daerah Provinsi Kalimantan Tengah sebagai berikut :

Tabel 4.53. Rekapitulasi tanggapan responden dari hasil angket mengenai Analisis Kinerja PegawaiNegeri Sipil pada Biro Pemerintahan dan Otonomi Daerah Sekretariat Daerah

\begin{tabular}{|c|c|c|c|c|c|c|c|c|c|c|}
\hline \multicolumn{11}{|c|}{ Provinsi Kalimantan Tengah } \\
\hline \multirow[t]{2}{*}{$\begin{array}{l}\text { Indkator } \\
\text { Penelitian }\end{array}$} & \multicolumn{2}{|c|}{ Sangat baik } & \multicolumn{2}{|c|}{ Baik } & \multicolumn{2}{|c|}{ Cukup baik } & \multicolumn{2}{|c|}{ Tidak baik } & \multicolumn{2}{|c|}{$\begin{array}{c}\begin{array}{c}\text { Sangat tidak } \\
\text { baik }\end{array} \\
\end{array}$} \\
\hline & Org & $\%$ & Org & $\%$ & Org & $\%$ & Org & $\%$ & Org & $\%$ \\
\hline $\begin{array}{l}\text { Pengetahuan } \\
\text { tentang } \\
\text { pekerjaan }\end{array}$ & 67 & $24 \%$ & 86 & $31 \%$ & 81 & $29 \%$ & 44 & $16 \%$ & 2 & $1 \%$ \\
\hline Kualitas kerja & 60 & $21 \%$ & 78 & $28 \%$ & 81 & $29 \%$ & 56 & $20 \%$ & 5 & $2 \%$ \\
\hline Produktivitas & 33 & $12 \%$ & 90 & $32 \%$ & 78 & $28 \%$ & 74 & $26 \%$ & 5 & $2 \%$ \\
\hline Adaptasi & 28 & $10 \%$ & 79 & $28 \%$ & 79 & $28 \%$ & 94 & $34 \%$ & 0 & $0 \%$ \\
\hline $\begin{array}{l}\text { Inisiatif } \\
\text { pemecahan } \\
\text { masalah }\end{array}$ & 38 & $14 \%$ & 91 & $33 \%$ & 88 & $31 \%$ & 63 & $23 \%$ & 0 & $0 \%$ \\
\hline Kerjasama & 39 & $14 \%$ & 109 & $39 \%$ & 81 & $29 \%$ & 51 & $18 \%$ & 0 & $0 \%$ \\
\hline Tanggungjawab & 41 & $15 \%$ & 76 & $27 \%$ & 93 & $33 \%$ & 70 & $25 \%$ & 0 & $0 \%$ \\
\hline $\begin{array}{l}\text { Kemampuan } \\
\text { dalam } \\
\text { berkomunikasi } \\
\text { dan } \\
\text { berinteraksi }\end{array}$ & 39 & $14 \%$ & 72 & $26 \%$ & 94 & $34 \%$ & 75 & $27 \%$ & 0 & $0 \%$ \\
\hline Jumlah & 345 & & 681 & & 675 & & 527 & & 12 & \\
\hline $\begin{array}{l}\text { Persentase } \\
\text { Rata-rata }\end{array}$ & $15 \%$ & & $30 \%$ & & $30 \%$ & & $24 \%$ & & $1 \%$ & \\
\hline
\end{tabular}

Sumber : Data olahan hasil penelitian Tahun 2021
Dari tabel diatas dapat diketahui rekapitulasi tanggapan responden dari hasil angket penelitian mengenai Analisis Kinerja Pegawai Negeri Sipil pada Biro Pemerintahan dan Otonomi Daerah Sekretariat Daerah Provinsi Kalimantan Tengah bahwa :

a) Pengetahuan Tentang Pekerjaan. Berdasarkan Rekapitulasi tanggapan responden pada tabel 4.53 dapat diketahui bahwa pengetahuan tentang pekerjaan dinyatakan baik, yaitu sebesar 31\%. Dengan demikian pegawai mampu melaksanakan tugas yang diberikan, baik dengan menggunakan peralatan maupun informasi yang dapat mendukung tercapainya tujuan dari Instansi tersebut.

b) Kualitas Kerja. Berdasarkan Rekapitulasi tanggapan responden pada tabel 4.53 dapat diketahui bahwa kualitas kerja dinyatakan cukup baik, yaitu sebesar 29\%. Dengan demikian, tingkat ketelitian pegawai dalam mengerjakan tugas kategori cukup, sehingga dapat menyebabkan kualitas yang dihasilkan belum sesuai dengan target yang diinginkan.

c) Produktivitas. Berdasarkan rekapitulasi tanggapan responden pada tabel 4.53 dapat diketahui bahwa produktivitas dinyatakan baik, yaitu sebesar $32 \%$. Pegawai optimal melaksanakan tugas seefisien mungkin, hal ini sangat berdampak positif terhadap waktu menyelesaikan pekerjaan.

d) Adaptasi. Berdasarkan rekapitulasi tanggapan responden pada tabel 4:53 dapat diketahui bahwa adaptasi pegawai dinyatakan kurang baik, yaitu sebesar 34\%. Dengan demikian pegawai tidak mampu menyesuaikan diri dengan perubahan secara tiba-tiba dalam lingkungan kerjanya, baik itu berupa aturan yang baru ataupun informasi dan teknologi yang belum mereka kuasai, karena pegawai perlu waktu untuk menyesuaikan diri agar dapat memberikan hasil yang lebih baik.

e) Inisiatif dan pemecahan masalah. Berdasarkan rekapitulasi tanggapan responden pada tabel 4.53 dapat diketahui bahwa inisiatif dan pemecahan masalah dinyatakan baik, yaitu sebesar $33 \%$. 
Pegawai mampu mengantisipasi dan menyelesaikan permasalahan yang dapat terjadi kedepannya.

f) Kerjasama. Berdasarkan rekapitulasi tanggapan responden pada tabel 4.53 dapat diketahui bahwa kerjasama pegawai dinyatakan sudah baik, yaitu sebesar 39\%. Dimana pegawai maupun atasan telah melakukan kerjasama yang efektif dan kerjasama yang dilakukan tersebut berpengaruh positif terhadap hasil kerja. Kerena pegawai mempunyai kemampuan untuk bekerjasama dalam menyelesaikan setiap tugas yang diberikan.

g) Tanggung jawab. Berdasarkan rekapitulasi tanggapan responden pada tabel 4.53 dapat diketahui bahwa tanggung jawab pegawai dinyatakan cukup baik, yaitu sebesar $33 \%$. Dimana pegawai mampu menghargai jam kerja serta disiplin dalam melaksanakan tugas, hal ini tentunya akan berpengaruh terhadap hasil kerja.

h) Kemampuan dalam berkomunikasi dan berinteraksi. Berdasarkan rekapitulasi tanggapan respondenpada tabel 4.53 dapat diketahui bahwa kemampuan dalam berkomunikasi dan berinteraksi dinyatakan cukup baik, yaitu sebesar 34\%. Dimana pegawai mampu berkomunikasi dengan jelas dan tepat secara lisan maupun tulisan, sehingga mempermudah proses pekerjaan.

Pada akhirnya akumulasi keseluruhan Kinerja Pegawai Negeri Sipil pada Biro Pemerintahan dan Otonomi Daerah Sekretariat Daerah Provinsi Kalimantan Tengah dari 8 indikator terdapat 4 indikator kategori baik, 3 indikator kategori cukup baik dan hanya I indikator yang tergolong kurang baik. Hasil penelitian menggambarkan bahwa Kinerja Pegawai Negeri Sipil pada Biro Pemerintahan dan Otonomi Daerah Sekretariat Daerah Provinsi Kalimantan Tengah dapat dikatakan tergolong baik.

\section{KESIMPULAN}

Berdasarkan hasil dan pembahasan penelitian maka dapat diambil kesimpulan bahwa Kinerja Pegawai Negeri Sipil pada Biro Pemerintahan dan Otonomi Daerah Sekretariat Daerah Provinsi Kalimantan Tengah. Dari 8 indikator kinerja yang diuji terdapat 4 indikator kategori baik, 3 indikator kategori cukup baik dan hanya I indikator yang tergolong kurang baik.

Adapun saran dalam penelitian ini yakni disarankan kepada pimpinan/pengambil kebijakan untuk memberikan kesempatan pendidikan dan pelatihan bagi pegawai dalam rangka menigkatkan adaptasi pegawai yang tegrolong rendah terhadap situasi dan kondisi yang terus berkembang.

Agar gambaran hasil penelitian dapat dijadikan gambaran dasar dalam rangka pembenahan organisasi yang lebih baik dan optimal kedepannya.

\section{UCAPAN TERIMA KASIH}

Terimakasih yang tak lupa saya ucapkan kepada para Dosen pembimbing saya yang sudah bekenan meluangkan waktu untuk mengarahkan dan membimbing secara intens karya tulis saya ini. Serta pada pendamping penelitian yang terus mendorong dan membantu untuk diskusi terkait tesis ini dan para personil FISIPOL UM Palangkaraya yang sudah membantu saya dalam proses administrasinya.

\section{REFERENSI}

Arikunto,Suharsimi. 2002. Prosedur Penelitian, Jakarta : Rineka Cipta

Arikunto,Suharsimi, 2010. Prosedur Penelitian (Suatu Pendekatan Praktik). Jakarta : Rineka Cipta.

Febryansyah, Bayu. 2012. Kinerja Birokrasi Pemerintahan pada Dinas Perindustrian dan Perdagangan (Studi Kasus di Kecamatan Karimun). Pekanbaru. UIN SUSKA RIAU 
Fitri dayana, Elsa. 2012. Kinerja Pegawai Negeri Sipil pada Kantor Dinas Pendapatan Provinsi Riau. Pekanbaru. UIN SUSKA RIAU

Hasibuan, Malayu S.P, 2007. Manajemen Sumber Daya Manusia" Edisi Revisi ”.Bumi Aksara, Jakarta.

Henry, Nicholas. 1995. Administrasi Negara dan Masalah-masalah Publik, jakarta : rajawali Press.

Mahmudi, 2005. Manajemen Kinerja Sektor Publik. UPP AMP YPKN. Yogyakarta.

Mangkunegara, Anwar Prabu, 2005. Evaluasi Kinerja SDM, Bandung, Refika Aditama.

Manulang, Manajemen Sumber Daya Manusia, Ghalia Indonesia, Jakarta, 1996. Notoadmodjo, Soekidjo, 2003. Pengembangan Sumber Daya Manusia, Jakarta, Rhineka Cipta.

Prawirosentono, Suyadi, 1999. Manajemen Sumber Daya Manusia :

Ruky, Ahmad S, 2004. Sistem Manajemen Kinerja, Jakarta, PT. Gramedia Pustaka Utama.

Sedarmayanti, 200I. Manajemen Sumber Daya Manusia,, Bandung, Mandar Maju.

Simanjuntak, Payaman, 2005. Manajemen dan Evaluasi Kinerja, Jakarta : LPFE UI.

Sugiyono Prof, 2007. Metode Penelitian Administrasi, Bandung : Alfabeta. Sulistiyani, Ambar Teguh, 2003. Manajemen Sumber Daya Manusia, Yogyakarta, Graha IImu.

Sianipar, MM, 2000. Perencanaan Peningkatan Kinerja, LAN.

Siagian S.P, 2002. Kiat Meningkatkan Produktivitas Kerja, Jakarta : PT. Asdi Mahasatya.

Sinungan, Muchdarsyah. 2003 Produktivitas Apa Dan Bagaimana. Jakarta, Bumi Aksara. 